\title{
Formação stricto sensu em Serviço Social na Universidade Federal da Paraíba: análise de 40 anos por clusters
}

\section{Stricto sensu training in Social Work at the Federal University of Paraíba: analysis of 40 years by clusters}

\author{
Marinalva Conserva ${ }^{a}$ \\ (D) https://orcid.org/0000-0002-5592-6236 \\ Aline Maria Batista Machado ${ }^{a}$ \\ (D) https://orcid.org/0000-0002-1144-6011 \\ Alice Dianezi Gambardella ${ }^{a}$ \\ (D) https://orcid.org/0000-0003-4222-1269
}

Resumo: 0 artigo analisa a formação docente no Programa de Pós-Graduação em Serviço Social da UFPB ao longo dos seus 40 anos - o mais antigo do Nordeste. 0 estudo teve como base as 378 dissertações defendidas até o ano de 2019; adotou tratamento quanti-qualitativo e contou com o auxílio dos softwares Excel e NVivo para desenho de clusters para análise de conteúdo das temáticas. As categorias revelaram consonância com as linhas de pesquisa e inserção social.

Palavras-chaves: Pós-graduação. Serviço Social. Formação docente.
Abstract: The article analyzes teacher training in the Graduate Program in Social Work at UFPB throughout its 40 years - the oldest in the Northeast. The study was based on the 378 dissertations defended until 2019; adopted quantitative and qualitative treatment and counted on the help of Excel and NVivo software for the design of clusters for content analysis of the themes. The categories were in line with the lines of research and social insertion.

Keywords: Post-graduate. Social Work. Teacher education. 


\section{Introdução}

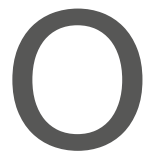

presente artigo objetiva dimensionar as contribuições, impactos e desafios na formação docente na área de Serviço Social, tendo como referência a construção de uma base de dados das dissertações defendidas ao longo de uma trajetória de 40 anos do Programa de Pós-Graduação em Serviço Social, da Universidade Federal da Paraíba (PPGSS/UFPB). A análise da relevância histórica do programa requer, sobretudo, compreendê-lo no processo de expansão da pós-graduação brasileira, no significado do papel que vem desempenhando, ao longo de sua trajetória, para consolidar a área de Serviço Social.

$O$ curso de mestrado acadêmico stricto sensu em Serviço Social na UFPB foi criado por meio da Resolução n 202/77 do Consuni/UFPB e implantado no ano de 1978, com credenciamento em 1985, através do Parecer no 754/85 do Conselho Federal de Educação. Consolida-se, assim, como o pioneiro na formação docente na área de Serviço Social, por ser o primeiro mestrado da região Nordeste e o quinto no país. A importância desse curso para a área nessa região foi perceptível durante toda a década de 1980 e visibilizada pelo impacto de sua produção acadêmica avaliado pela Coordenação de Aperfeiçoamento de Pessoal de Nível Superior (Capes) com o conceito A, durante toda a década de 1980, isto é, concedido pela instituição responsável pela política de capacitação docente e de reconhecimento e avaliação de cursos de pós-graduação stricto sensu.

O programa apresenta-se, desde a sua criação, com a proposta de atender à crescente demanda de formação docente das IES do Norte/ Nordeste, tendo como referência os diferentes processos sociais que dinamicamente configuram e reconfiguram a relação capital/trabalho e as expressões da "questão social".

A exposição que segue explicita a relevância e a historicidade de dados e exemplos que os comprovam. Nessa trajetória, ressaltamos a sintonia com traçados do Serviço Social no Brasil, que corresponde aos 
nexos com a leitura da realidade social, econômica e política do país e seu compromisso com as lutas e os direitos da classe trabalhadora. A partir de 2015 destaca-se na área de concentração as linhas de pesquisa, as publicações de resultados dos estudos de docentes e discentes, a integração com outros programas e instituições de pesquisa para a execução de políticas sociais e a internacionalização. Assim, o arcabouço de pesquisas em andamento se integra às necessidades apontadas pelos executores das políticas sociais e oferece subsídios com aprofundamento crítico para o avanço e a melhoria de ofertas no campo dos direitos sociais, em consonância com o Projeto Ético-Político do Serviço Social.

O pioneirismo do PPGSS/UFPB para a formação docente ao longo de seus 40 anos (1978-2020) impactaram tanto na criação de cursos e instituições de ensino superior do Norte/Nordeste quanto na consolidação da área do Serviço Social, porquanto se propôs a atender à crescente demanda de formação docente, de pesquisadores e de profissionais. Nessa direção, insere-se no campo de conhecimento, que contempla: os fundamentos teórico-metodológicos da formação e da prática profissional no Serviço Social; a relação entre Estado e sociedade, bem como entre os direitos sociais e contribuições relevantes no campo da gestão e da implementação de políticas sociais.

Este estudo analítico apresenta uma abordagem metodológica quanti-qualitativa, a partir de uma construção de um banco de dados que contempla um universo total de 378 dissertações defendidas no período de 1983 a 2019, no âmbito do PPGSS/UFPB. Essa base fora materializada em formato de catálogo de dissertações, ${ }^{1}$ referente aos quarenta anos do programa, em 2018, e, por sua, vez, consolidada em 2019, com

\footnotetext{
A elaboração do catálogo se deu por meio de Projetos de Pesquisas (Pibic), extensão e outros, por meio de grupos de pesquisas do PPGSS, coordenados pelas profas. dras. Maria do Socorro Souza Vieira e Bernadete de Almeida com discentes de graduação e pós-graduação nos anos de 2015 a 2018, consolidando assim o catálogo das dissertações (1983-2019), com a coordenação atual do PPGSS/UFPB.
} 
as seguintes informações coletadas de cada dissertação: título, resumo, palavra-chave, sumário, autor e orientador. Esse volume permitiu a construção deste estudo a partir de técnicas, software, programas e clusters de pesquisa. Por se tratar de análise documental, optamos por dividir as produções em quatro recortes temporais: a) 1983-9; b) 1990-9; c) 2000-9; d) 2010-9. Ademais, as representações estatísticas descritivas simples foram trabalhadas no software Excel e as representações descritivas imagéticas acerca do teor das produções acadêmicas foram elaboradas com o auxílio do NVivo.

\section{Impactos da formação stricto sensu na área de Serviço Social}

A atuação acadêmica do PPGSS/UFPB ganhou relevância histórica não apenas pela capacidade de atender a uma grande demanda reprimida de formação docente interdisciplinar das regiões Norte e Nordeste, mas, sobretudo, por ser um espaço de amplo debate de atuação político-acadêmica que fomentava e fermentava a luta pela redemocratização do país. Tratava-se de uma proposta, conforme já anunciado, à frente de seu tempo, ao se afastar dos atributos conservadores, ainda presentes nos demais programas criados nas décadas de 1970 e 1980. Nesse período, houve forte expansão das instituições públicas, tanto no âmbito da graduação quanto no da pós-graduação brasileira.

A expansão inicial, nas décadas de 1970 e 1980, é parte de um processo em curso no país. Nesse período, as principais agências de financiamento de pesquisa (Coordenação de Aperfeiçoamento de Pessoal de Nível Superior - Capes e Conselho Nacional de Desenvolvimento Científico e Tecnológico - CNPq) incluem o Serviço Social como área de conhecimento, momento de configuração do Sistema Nacional de Pós-Graduação e de elaboração do primeiro Plano Nacional de Pós-Graduação. (Brasil, 2019, p. 3-4) 
O Movimento de Reconceituação do Serviço Social na América Latina demarcou os processos de ruptura com o conservadorismo, tanto no âmbito da formação profissional quanto na formação de pesquisadores e docentes na área de Serviço Social. Daí destaca-se a importância do programa na formação de professores do curso de graduação em Serviço Social da UFPB, que atingiu a marca de 65 anos de história na formação acadêmica na área, no estado da Paraíba e na região Nordeste, com exitosos resultados. Ao ilustrar essa relevância, destaca-se que, dos 38 docentes do Departamento de Serviço Social da UFPB, 25 obtiveram o título de mestre no PPGSS/UFPB. O impacto e as repercussões também podem ser observados na consolidação do curso de graduação em Serviço Social da Universidade Estadual da Paraíba, na cidade de Campina Grande. Dos vinte docentes efetivos naquele curso, onze foram formados ou tiveram vínculo no quadro do PPGSS/UFPB. Isso reitera não apenas o impacto dessa pós-graduação na formação de quadros docentes pelo estado e pela região, mas, sobretudo, a absorção de alunos "egressos" no próprio corpo docente.

O programa em sua trajetória apresenta um relevante papel na formação docente e profissional, com incremento da produção acadêmica e técnica para o Serviço Social e áreas afins. Sua proposta consiste em estimular estudos e pesquisas que avaliem e alimentem as estratégias de construção e gestão das políticas sociais, na perspectiva de proporcionar transformações societárias emancipatórias e de superação das desigualdades sociais. Esse lugar assumido, ganhou notoriedade com a criação do programa stricto sensu de pós-graduação em Serviço Social na Universidade Estadual da Paraíba, recém-criado na cidade de Campina Grande (2013). Em seu corpo docente permanente existem professores que obtiveram o título de mestres no PPGSS.

A partir de 2012, o programa iniciou um processo de reestruturação acadêmica com impactos relevantes em sua estrutura curricular, que se consolidou no ano de 2016 com a aprovação da Resolução n 01/2016 do 
Consepe/UFPB. Apresenta-se atualmente, com uma única área de concentração - Serviço Social e política social, estruturada em duas linhas de pesquisa: L1 - Serviço Social, trabalho e política social. L2 - Estado, direitos sociais e proteção social.

Essa dinâmica empreendida possibilitou consolidar uma política de aprimoramento do programa em termos de: área de concentração, estrutura curricular, linhas de pesquisa, configuração de grupos e núcleos de pesquisa, elaboração de critérios de credenciamento e descredenciamento de docentes, incentivo à qualificação docente com estímulo à realização de estágio pós-doutoral dentro e fora do país, e apoio à produção acadêmica por intermédio de incentivos à publicação dos resultados de pesquisas produzidas pelo programa com parcerias institucionais em âmbito nacional e internacional.

Nesse contexto, outras iniciativas de atuação acadêmica foram desencadeadas no PPGSS/UFPB, com destaque para a consolidação de uma rede de cooperação acadêmica em âmbito nacional, a partir da aprovação do Projeto Casadinho/Procad/CNPq/Capes, por meio de uma ação transversal intitulada "Assistência social e transferência de renda: interpelações no território da proteção social”, de no 552248/2011-18 (2012-17), na perspectiva de elevar o padrão de qualidade da formação acadêmica e de contribuir para consolidar a área de Serviço Social no âmbito da pós-graduação.

Em 2018, de modo especial, o PPGSS, através da atuação de docentes e de grupos de pesquisas, apresentou importantes ações em consonância com o programa institucional da UFPB, especialmente a partir da aprovação do Programa Institucional de Internacionalização Capes-Print no referido ano, que estimulou o programa a investir no processo de internacionalização, a exemplo da parceria com a Universidade de Salamanca - Usal (Espanha), tanto por meio de articulação e promoção de eventos científicos, envolvendo professores de ambas as universidades, como na possibilidade de professores visitantes estrangeiros no PPGSS/UFPB. 


\section{Análises de clusters dos quarenta anos de dissertações}

A relevância do PPGSS/UFP apresenta maiores impactos não só pelo acervo de 378 dissertações defendidas até dezembro de 2019, mas, principalmente, pelo crescente avanço ascendente linear, sobretudo a partir de 2005, conforme demonstram os gráficos (1 e 2).

Os gráficos indicam que mais de $50 \%$ das titulações e defesas de mestrado foram elaboradas no decorrer da última década, indicando os resultados esperados para a consolidação do programa, sobretudo quanto à formação de profissionais, docentes e profissionais do campo da assistência social no estado da Paraíba.

Gráfico 1. Avanço das titulações associadas à defesa de dissertações. PPGSS/UFPB, 1983-2019

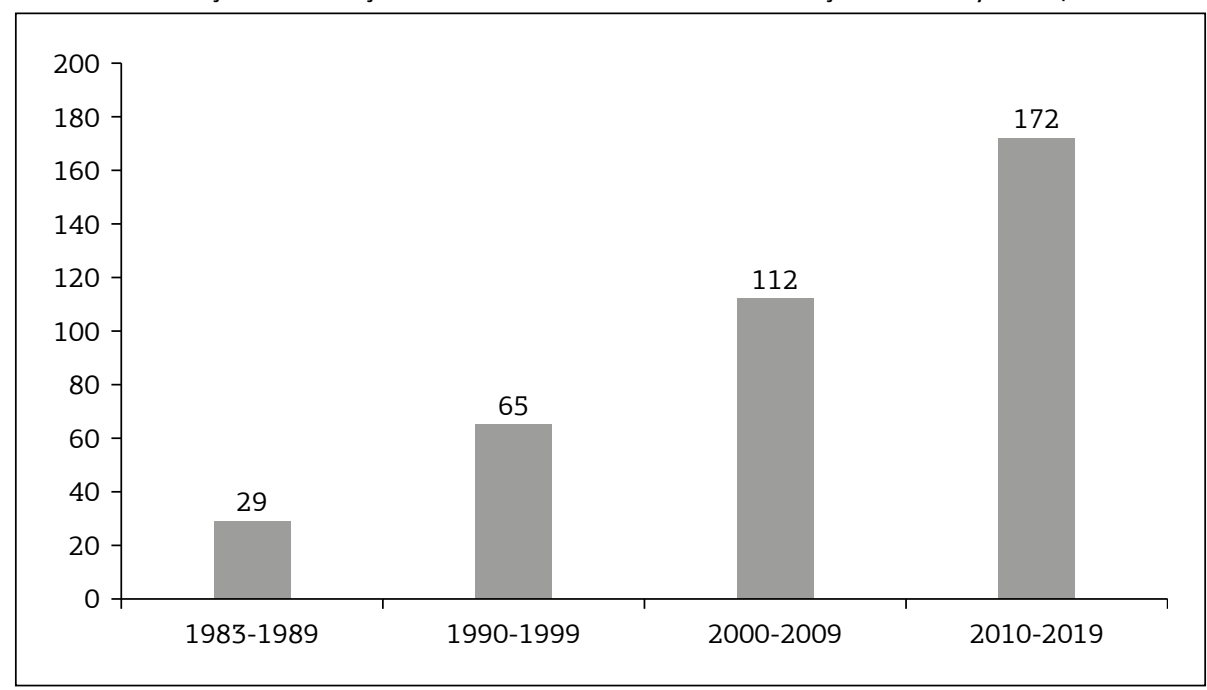

Fonte: Elaboração própria com base em dados do Catálogo dos 40 anos PPGSS/UFPB, 2019.

Revelam ainda que $24,8 \%$ (94 dissertações) foram defendidas entre as décadas de 1980 e 1990, sendo que a maioria significativa de 75,1\% (284 dissertações) se concentra nas décadas de 2000 e 2010. Nesse sentido, deve-se salientar que os anos de 2010 e 2015 se destacam em relação 
ao número de defesas, 22 e 27 respectivamente, impactos atribuídos ao Projeto Casadinho/Procad/Capes/CNPq.

Os estudos e pesquisas abordados nas dissertações que consubstanciaram o programa revelam temáticas que versam sobre os seguintes eixos e linhas: política social, trabalho social, programas sociais, proteção social, prática profissional, direitos sociais, crianças, adolescentes e famílias, conforme Gráfico 1, refletindo esse duplo caráter do programa em sua área de concentração e em suas duas linhas de pesquisa. Nele destaca-se sobretudo as categorias: serviço social, trabalho, política social e pesquisa, o demonstra articulação entre as linhas de pesquisa do programa.

Gráfico 2. Frequência das titulações por ano. PPGSS/UFPB, 1983-2019

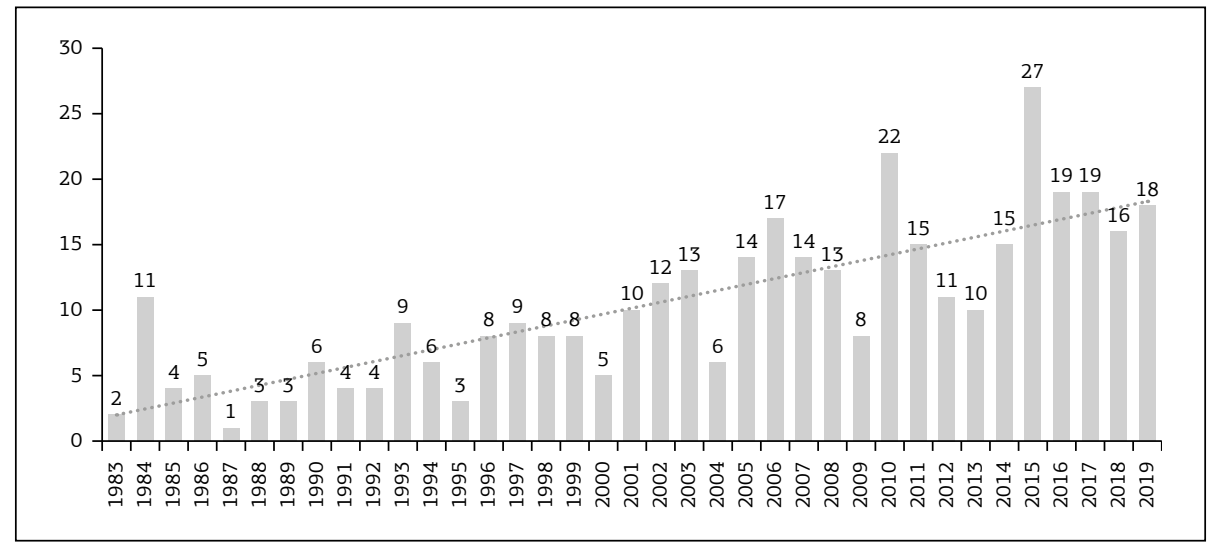

Fonte: Elaboração própria com base em dados do PPGSS/UFPB, 2019.

Vale ressaltar que as análises descritivas elaboradas década a década são parcialmente diferenciadas do conjunto produzido pelo programa ao longo de sua trajetória, permitindo identificar os movimentos pelos quais discentes e docentes vieram colaborando com sua construção e permanência tão significativos para a região nordeste do país e, em especial, ao estado da Paraíba

As imagens de clusters (Gráfico 3) revelam que os anos iniciais do PPGSS produziram pesquisas bastante alicerçadas na relação 
Gráfico 3. Cluster da frequência das temáticas abordadas em dissertações por década do PPGSS/UFPB, 2019

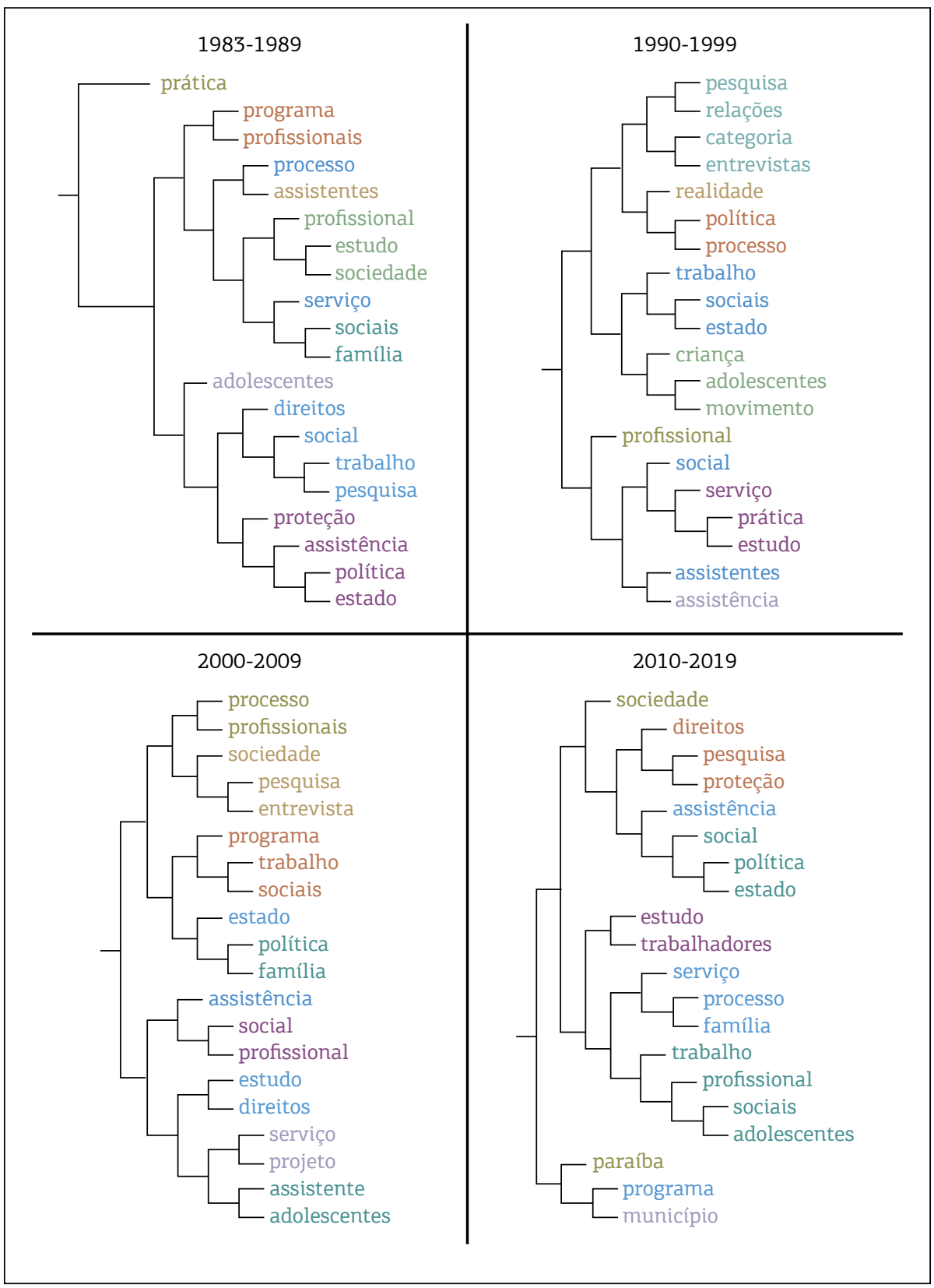

Fonte: Elaboração própria, com base em dados do PPGSS/UFPB, 2019. 
ensino-pesquisa- extensão. Partem do eixo da prática profissional para o campo em temáticas variadas, desde o tipo de pesquisa acadêmica e métodos de intervenção, grupos etários e famílias e mesmo a prática profissional no âmbito acadêmico, conforme a linha de fundamentos do Serviço Social que permanece até os dias atuais.

Os clusters expressam mais detalhadamente a correlação entre as abordagens e o teor das pesquisas em dissertações, cujo principal elemento desencadeador se deu a partir da prática profissional, embora tenha sido um estopim para os estudos acerca do Estado e das políticas públicas e sociais focadas na proteção social, a partir da família, da prática profissional, da assistência social e do trabalho profissional.

Esse processo foi inaugurado no período 1990-99, quando a expressão da pesquisa acadêmica stricto sensu ganha densidade, incorporando as temáticas supracitadas por meio do viés acadêmico, numa perspectiva mais horizontalizada com os estudos da prática profissional.

Nos anos que compreenderam o período 2000-09, é possível notar o equilíbrio entre essas duas vertentes - trabalho profissional e pesquisa acadêmica - , com notas de práxis em que temáticas de pesquisa e trabalho profissional caminham em conjunto, lado a lado. Nesse momento, a prática profissional se atrela à política de direitos por um lado e, por outro lado, as pesquisas e métodos remetem ao Estado e à sociedade em geral.

A última década, que compreendeu os anos entre 2010 e 2019, dá seguimento às premissas temáticas consolidadas até então, mas com um diferencial expoente: o destaque sobre o campo, o espaço, o território em específico, pela organização geopolítica dos municípios, com destaque para o estado da Paraíba.

\section{Considerações finais}

O contexto atual da pós-graduação, tanto em nível nacional quanto internacional, requer não apenas um patamar de superação na dinâmica 
dos processos de formação de docentes e pesquisadores para as universidades e para o próprio sistema acadêmico, mas também na produção de novas competências e ferramentas em função das demandas de sociedades tão díspares e desiguais, tanto em termos socioeconômicos quanto no campo emancipatório dos direitos sociais e de cidadania. Ou seja, são necessárias, em termos de planejamento estratégico dos programas, diretrizes de atuação político-acadêmica que impactem na relação Estado/sociedade, em especial na formulação, no planejamento e na gestão das políticas públicas. Foi justamente nessa perspectiva que o PPGSS/UFPB definiu suas diretrizes em sua atuação de 2018, bem como desenvolveu seu planejamento estratégico para o quadriênio em curso (2018-20).

A inserção social configura-se como um dos indicadores que caracterizam o PPGSS/UFPB ao longo de sua relevante trajetória, por expressar em suas produções acadêmicas os compromissos ético-pedagógico com o enfrentamento das expressões da questão social que ganham maior relevância na região Nordeste e, ao mesmo tempo, construir ferramentas que possam incidir no redirecionamento das políticas de proteção social. É mister avaliar os processos de estudos investigativos desenvolvidos no âmbito da região, mas também contribuir com o escopo de ferramentas que impactem e tenham repercussões nas mudanças na realidade social e na capacidade que seus resultados têm de subsidiar as políticas públicas de proteção social, em territórios tão díspares e desiguais, tanto em relação ao acesso como à garantia de seu caráter protetivo dos direitos sociais. Registramos um importante projeto de estudo coordenado pelo Nepps/PPGSS, em parceria com a Secretaria de Estado do Desenvolvimento da Paraíba, que resultou na publicação da obra intitulada Topografia social regionalizada do estado da Paraíba, em 2016, na versão impressa, e reeditada no formato digital em 2017 (www.neppsufpb.com.br). Essa ferramenta inédita de gestão, construída em nível estadual, foi uma referência para diversas políticas públicas, especialmente a regionalização da política estadual de assistência social, sob a responsabilidade da SEDH-PB. 
Nessa perspectiva, ressaltamos a criação da plataforma digital "Rede Criança PB”, resultado de pesquisas do programa em 2018. A Rede Criança PB (http://redecrianca.pb.gov.br/) é gerenciada diretamente pelo Conselho Estadual de Defesa dos Direitos de Crianças e Adolescentes da Paraíba (Cedca) e, nos municípios, pelos seus respectivos conselhos municipais, com o apoio e a colaboração dos conselhos estaduais e municipais de Assistência Social, Educação e Saúde.

Atualmente o PPGSS vivencia um processo de consolidação de sua internacionalização em consonância com o planejamento institucional da UFPB, com forte investimento em recursos humanos, como quando do lançamento de edital de professor visitante (2018-19), que levou à contratação de mais cem professores visitantes. Nessa oportunidade, o PPGSS galgou duas vagas inéditas de professores visitantes, o que, certamente, produzirá impactos relevantes tanto na formação de mestres e pesquisadores como na manutenção da qualidade da produção acadêmica do programa.

Essa dinâmica institucional no âmbito da UFPB vem se constituindo com estratégias de resistências diante do desmonte atual, principalmente no âmbito da pós-graduação brasileira. Assim, o programa vem apresentando uma dinâmica de reestruturação e reorganização na perspectiva de afirmar o seu protagonismo histórico na formação de recursos humanos e consolidação na área do Serviço Social no âmbito acadêmico-científico e institucional, com relevante contribuição na formação docente, bem como para a gestão de políticas sociais, por meio da participação ativa de seu corpo docente e discente, com política de acompanhamento de egressos na implementação e gestão de políticas sociais, especialmente nas esferas municipal e estadual. Cabe aqui registrar a efetiva participação de egressos na: (i) docência e coordenação de cursos de graduação e pós-graduação na área de Serviço Social; (ii) inserção em cursos de doutorado em todas as regiões, haja vista que no estado da Paraíba não existe nenhum curso na área de Serviço Social; (iii) efetiva participação como egresso, pesquisador nos grupos de pesquisa do programa; 
(iv) atuação na gestão das políticas sociais públicas (gestores, secretários municipais, estaduais e até em cargos eletivos, a exemplo da prefeita do município de Conde (a dezoito quilômetros da capital). Em 2019, esses dados ganham relevância com uma docente colaboradora do PPGSS/ UFPB eleita deputada estadual.

Diante do exposto, cabe refletir sobre as estratégias, perspectivas, tendências e desafios para área e, de modo particular, para o PPGSS/ UFPB, considerando as similitudes, diferenças e assimetrias regionais. Ou seja: a construção desses indicadores de autoavaliação no âmbito de um lugar privilegiado de produção do conhecimento, dada a centralidade da pesquisa científica, exige também refletir sobre o conhecimento que vem sendo produzido em sua capacidade de análise crítica de temas como a questão social e as políticas sociais na contemporaneidade, mas sobretudo em sua competência em responder a essas questões, em termos do avanço teórico-metodológico do Serviço Social em suas conexões com a realidade social em que essa profissão e seus serviços estão possibilitando ou contribuindo na mediação das políticas públicas de proteção social, em conformidade com os eixos basilares desta área de conhecimento.

\section{Referências}

BRASIL. Coordenação de Aperfeiçoamento de Pessoal de Nível Superior. Documento de Área, Área 32: Serviço Social. Brasília, 2019.

CONSERVA, M. et al. Topografia Social Regionalizada do Estado da Paraíba. 2016.

PROGRAMA DE PÓS-GRADUAÇÃO EM SERVIÇO SOCIAL. Catálogo dos 40 Anos do PPGSSUFPB. Base de dados 2019.

PROGRAMA DE PÓS-GRADUAÇÃO EM SERVIÇO SOCIAL. Seminário dos 40 anos do PPGSS. Relatório interno.

PROGRAMA DE PÓS-GRADUAÇÃO EM SERVIÇO SOCIAL. Síntese de formulário do egresso, 2018-2019. Relatório interno. 


\section{Sobre as autoras}

Marinalva Conserva - Doutora pela Universidade Federal do Rio de Janeiro e pós-doutorado em Serviço Social pela Pontifícia Universidade Católica de São Paulo; coordenadora do Núcleo de Estudos e Pesquisas em Políticas Sociais (www. neppsufpb.com.br).

E-mail: mconserva@uol.com.br

Aline Maria Batista Machado - Assistente social, mestre em Serviço Social e doutora em Educação, docente do Departamento de Serviço Social e vicecoordenadora do Programa de Pós-Graduação em Serviço Social; coordenadora do Grupo de Estudos e Pesquisas em Educação Popular, Serviço Social e Movimentos Sociais.

E-mail: prof.alinemachado23@yahoo.com.br

Alice Dianezi Gambardella - Doutora em Serviço Social pela Pontifícia Universidade Católica de São Paulo PUC-SP; bolsista/pesquisadora em Políticas Sociais (Nepps). Foi consultora PNUD acerca de eventos emergenciais e de calamidade pública (2018-9), incluindo os casos das empresas Samarco e Vale. E-mail: alicedigam@gmail.com 